Research Article

\title{
Clustering Analysis of Risk Divergence of China Government's Debts
}

\author{
Tianhao Ouyang $(\mathbb{D}$ and Xiaoyong Lu \\ Management School, Nanchang University, Nanchang, Jiangxi 330031, China \\ Correspondence should be addressed to Tianhao Ouyang; t.ouyang@email.ncu.edu.cn
}

Received 28 July 2021; Revised 10 August 2021; Accepted 17 August 2021; Published 31 August 2021

Academic Editor: Mian Ahmad Jan

Copyright $\odot 2021$ Tianhao Ouyang and Xiaoyong Lu. This is an open access article distributed under the Creative Commons Attribution License, which permits unrestricted use, distribution, and reproduction in any medium, provided the original work is properly cited.

It is a difficult time for the world's economics while the impact of COVID-19 is undergoing. A possible worldwide sovereign debt crisis could emerge, in short term, for supply chains blockage due to its slowing-down in many countries. China, having the second largest economy in the world, is crucial for the stability and sustainability of the economic recovery. China endures a longterm growth since 2000; nevertheless, a large amount of that growth is contributed by the government debt, which was spent on infrastructures. The accumulation of debts is a potential risk to the future growth of China. This research evaluates the central government and local government debts with a series of indicators. The weights of indicators are determined by objective methods of the CRITIC approach. Results confirm that the central government debt of China is on the edge of risk, while the risk of local governments debt is already in a concerning danger. The local government risk is $50 \%$ higher than the central government's risk. Moreover, the $K$-means clustering algorithm performed on data, collected from various provinces, suggests that the local government debts of China follow a pattern of geographical distribution; that is, the closer to the coast, the lesser the risk, which is in accordance with the pattern of labor flowing. Labors are attracted by job opportunities which lie in the well-developed regions of China. This is confirmed by the crosscheck with the wage growth data. This indicates that the less developed areas of China rely more heavily on debt-investment stimulation that could be of a potential stagnation because the yield of investment follows diminishing marginal returns and the relative lacking labor weakens the potential economic growth.

\section{Introduction}

Government debt has been a crucial factor in stability of governments and world economy. Usually when nations are not able to pay their debts, a particular nation would choose to "default" the debts if there is no more desperate action such as waging wars. Default on debt will drastically increase the borrowing costs because creditor requires higher interest rates to compensate the possibility of receiving nothing. The higher debt service costs will further decrease the nation's fiscal expenditure, especially in investments, which will crush the potential economic growth. That is what we observed in most debt crisis, such as the cases of Latin America and the 2008 sovereign debt turmoil in Europe. Furthermore, the debt crisis does not harm the default country, only, but the debt risk is contagious at regional level if it is not a global one [1].
China had enjoyed a long-term economic growth for the last decades. However, the potential growth rate of China becomes lower than $6 \%$ compared with the twofigure growth. From the second decade of 21st century, China depends on investments much more, and the large share of the investments is from the government (including local governments). Yet, the investment follows the law of diminishing returns, making investment less economic efficient. Thus, government debts start to accumulate fast. The government debt of China (including local governments) is more than 38 trillion Chinese Yuan. Comparing to the Gross Domestic Products (GDP) of about 100 trillion Yuan, the debt may not be an immediate and direct threat. The fast growth makes the debt risk a potential debt when the world economy was disrupted by the COVID-19 pandemic. Meanwhile, China now becomes the largest creditor in the world [2]. This suggests that the fiscal 
situation would decide the debt relief decisions on counties with heavy burden of debts.

Sovereign debt problem is not a new problem; from historical perspective, it is rare when there is no country to default their debts [3]. Though the foreign debt default usually causes international quarrel and conflict, the domestic debt's risk should not be underestimated [4]. Also when export takes a large share in nation's economic engine, the sovereign debt is vulnerable to international shocks [5]. For a large economic country like China, the foreign debt to total debt ratio is now much lower compared to the 1980s when the country requires immediate investment to stimulate the economic development. Note that China has gone through a certain economic transformation that significantly reduced their dependency on exporting, while the domestic consumption starts to rise.

The research about sovereign debt focuses on the risks it brought to other political and financial systems. While a market rich is in liquidity, stock market is easy to be endangered by the debt risk [6]. What follows is the bond market, which is directly linked with the government debt. Since most part of the government bond is traded in the domestic bond market, and based on the study about spreads of local currency bonds, the domestic debt risk is lower than foreign debts [7]. However, according to the study on Europe debt crisis, domestic banks of debt-stressed country would buy in more bonds that does not really ease the issue but buy more time for the nation to deal with the debt crisis [8]. Therefore, close risk monitoring and evaluation on the government debt is necessary. Mao et al. found that a debt crisis would transfer into a financial crisis, by the domestic commercial banks factor, as the debt crisis in Europe can be considered as an outcome of the 2008 financial crisis [9].

How to regulate the finance system is also an important topic discussed in the debt research. From the experience of Europe debt crisis, the right way would be setting more firewalls between the financial products. Research indicates that for the post-debt crisis in European counties, CDs and bonds in their markets have lower statistical cointegration [10]. Yet, the fundamental action would be reforming the fiscal situation. The mainstream of the field considers that the optimal fiscal policy would be procyclical actions [11]. Meanwhile, contractionary fiscal policy is also advocated by many researchers who believe high debt to the GDP ratio will force the interest rate to go up, based on the model study [12]. Moreover, Croce et al. [13] believe that cutting the balance of debt will increase the output and welfare level (2021). Nevertheless, in general, scholars are aware of incoming debt crisis. They call for more rigid fiscal rules while many economies are disrupted by the COVID-19 pandemic [14]. Afterall, both the procyclical and anticyclical fiscal policies require rigorous reviews and carry-outs. This research is an investigation of the China governments debts including both the central and the local. Methods such as $\mathrm{K}$ means clustering are used on real datasets to obtain certain findings. Following are the major contributions of the research conducted in this paper:

(1) We evaluate the debt risks for both the central government and local government of China
(2) The methods of evaluation; that is, $K$-means clustering is implemented over real datasets to obtain certain findings

(3) We conclude that the central government debt of China is on the edge of risk, while the risk of local governments debt is already in a danger

(4) The local government risk is $50 \%$ higher than the central government's risk; and the local government debts of China follow a pattern of geographical distribution

The structure of the remaining part of this paper is as follows. Section 2 describes the details of the research methodology. In Section 3, we discuss the outcomes of our results that are based on a clustering method, that is, $K$-mean clustering approach. Section 4 describes our research findings. Finally, Section 5 concludes this paper along with several directions for future research.

\section{Research Methodology}

Various risk indicators are used to reach an accurate and precise evaluation. Below we describe different indicators both for local and central governments and how these indicators are computed, and what kind of risk they reflect. At last, we describe the $K$-means clustering technique, briefly.

2.1. Central Government Indicators. The central government debt risk can be divided into 6 risk indicators from $\left(R_{11}\right.$ to $R_{16}$ ) to reach an accurate and precise evaluation. Below are how these indicators organized, and what kind of risk they reflect. $R_{11}$ is calculated by dividing the fiscal deficit to GDP, which evaluates the fiscal deficit's share in the overall economic activity of a year. That also can be interpretated as how much a nation's economic relies on financial deficit. For this indicator, a lower value means a lower risk. $R_{12}$ is bond issuing volume divides fiscal expenditure, evaluating how much a government's expenditure relies on borrowing. Also, the lower is the better. Usually, the benchmark of $R_{12}$ is set to $25 \%$. However, considering the bonds of China local governments are endorsed by the central government (the market and everybody strongly believe so), the central government bond issuing volume to fiscal expenditure ratio $R_{12}$ is set to $15 \%$. For local governments, the same risk indicators will be evaluated using $R_{12} . R_{13}$ checks the pressure from debt service, by dividing the debt service with fiscal income. The higher the $R_{13}$, the higher the risk, because the government must use a larger share of their income to pay debts and interests.

$R_{14}$ is constructed in the same manner as $R_{11}$, which is the ratio of bond issuing volume to GDP, which represents how much the economic running relies on the government borrowing of a year. The lower is the better, as well. According to the rule of thumb, the benchmark line is set on $3 \%$. There is no strict theoretical explanation about that number. Researchers and studies choose the "3\%" that could be influenced by the "Treaty of Maastricht" from Europe. The Treaty established economic and fiscal standards for those countries wish to join 
the European Union (EU). For instance, a country cannot have a high inflation rate and a fiscal deficit higher than $3 \%$ of their GDP. Although, since 2008, China started to enact proactive fiscal policies, their $R_{14}$ are well controlled by under $3 \%$ (the benchmark was breached for only two times). Meanwhile, many major nations have higher rates than $3 \%$. Considering the impact of the COVID-19 pandemic, many nations rely on the borrowing much more than before. The benchmark of $R_{14}$ still sticks to $3 \%$.

$R_{15}$ is constructed by dividing bond issuing volume with deposits outstanding. Government bond is a kind of borrowing; thus, creditors who provide cash funding are required for the equation. Deposits outstanding is the money which can purchase bonds. A low $R_{15}$ ratio indicates more money is available to do the purchase. Though the interest rates can evaluate the money shortage level, their rapid fluctuations make it difficult to be a reliable indicator. The interest rates are influenced by many other markets such as stock and real estates. The bond issuing volume to deposits outstanding ratio is a more objective indicator to reflect the risk of borrowing. Furthermore, $R_{16}$ is a crucial indicator measuring the balance of a nation debt to its GDP. For developed countries, currently their $R_{16}$ are way ahead of $100 \%$ or even higher. For instance, since Japan's bubble economy burst in late 1980s, the Japanese government relied highly on borrowing (yet the stimulation effect was not so satisfying). The GDP per capita stays still for a long while; thus, the saying of "the lost decade/decades" arose. Nowadays, the debt to the GDP ratio of Japan is larger than $270 \%$, which reflects that $R_{16}$ is a significant indicator (refer to Table 1 for various indicators).

The GDP or $R_{16}$ ratio is also an important fiscal criterion of joining the EU, by setting the benchmark as $60 \%$. In this research, the benchmark is lift to $70 \%$, because the nations around the world have higher debt to GDP ratios than a decade ago. For instance, the United States now reaches $128 \%$. Similarly, the foreign debt to GDP ratio of Japan is over $92 \%$. Traditional developed countries in Europe also suffer from high debt level: Germany 78\%, Netherlands 75\%, UK 102\%, France $114 \%$, Spain $118 \%$, Italy $160 \%$, Belgium $122 \%$, and Greece (which been criticized a lot by EU countries) 213\%. Meanwhile, a promising country that attract many foreign companies to set their headquarters, Ireland, also has a high debt ratio of $90 \%$. It can be concluded that the benchmark set by $\mathrm{EU}$ has been penetrated by almost all EU nations. Therefore, in this research, we lift the benchmark value of $R_{16}$ to $70 \%$, which will not underestimate the potential risk, for China that has a much lower debt ratio. Considering the international financial market is functioning well so far, the portfolios will invest more on Chinese government bonds while others are too risky. The central government debt risk indicators are shown in Table 1.

2.2. Local Government Indicators. The indicators introduced above in Section 2.1 sum up the central government debt risk evaluation. They are organized into Table 1. For the local government debt risk, the indicators are constructed in the same manner with the central government evaluation. $R_{21}$ to $R_{24}$ are identical with $R_{11}$ to $R_{14}$, while $R_{25}$ is constructed in the same way as $R_{16}$. They are highlighted in Table 2.

2.3. The CRITIC Method. As shown in Tables 1 and 2, all indicators have their own weights. That was calculated by the CRITIC method (Criteria Importance Through Intercriteria Correlation), which can handle the issuance of indicators having the same elements efficiently. For $R_{11}, R_{14}$, and $R_{16}$, they have the same element of GDP. Thus, GDP has influence on the values of these indicators. That is why CRITIC was introduced because it can measure information entropies (while evaluating the level of correlations) and calculates the redundancy of indicators. So, when few indicators are correlated on a certain level (making them provide less information), their weights will be trimmed in CRITIC method. Again, $R_{11}, R_{14}$, and $R_{16}$ all have the elements of GDP, but they also evaluate the fiscal deficit, bond issuing volume, and debt balance, which implies that these indicators cannot be further simplified. By introducing CRITIC, the problem of correlated indicators can be balanced, and the final weights can be well balanced with the objective. Below are how weights calculated by the CRITIC method [15].

Say there are $n$ samples, and each sample is regulated by $p$ indicators and that can be denoted as a matrix $A$ in equation (1), where $u_{i j}$ is the indicator value of number $j$ (of the sample $i$ ).

$$
A=\left|\begin{array}{cccc}
u_{11} & u_{12} & \ldots & u_{1 p} \\
u_{21} & u_{22} & \ldots & u_{2 p} \\
\ldots & \ldots & \ldots & \ldots \\
u_{n 1} & u_{n 2} & \ldots & u_{n p}
\end{array}\right|
$$

All indicators need to be nondimensionalized by Maxbest or Min-best (larger value the better or less value the better). Considering this research focus on risk evaluation with the indicators introduced in Tables 1 and 2, indicator value should be handled with Min-best by equation (2). For simplicity, $u_{i j}^{\prime}$ after equation (2) will still be denoted as $u_{i j}$.

$$
u_{i j}^{\prime}=\frac{u_{\max }-u_{j}}{u_{\max }-u_{\min }}, \quad(j=1,2, \ldots, N) .
$$

Then, the standard deviations of indicators $S_{j}$ need to be evaluated by the following equation, while $\overline{u_{j}}=1 / n \sum_{i=1}^{n} u_{i j}$.

$$
S_{j}=\sqrt{\frac{\sum_{i=1}^{n}\left(u_{i j}-\overline{u_{j}}\right)^{2}}{n-1}} .
$$

The conflicts of indicators $R_{j}$ need to be calculated by equation (4), while $r_{i j}$ is the correlation coefficient between indicator $i$ and $j$. The larger the $r_{i j}$, the more redundance in indicators $i$ and $j$, which means they provide less information. And their weight should be less in the overall indicators.

$$
R_{j}=\sum_{i=1}^{p}\left(1-r_{i j}\right)
$$


TABLE 1: The central government debt risk indicators.

\begin{tabular}{lccc}
\hline Indicators & Definitions & Weights & Benchmark (\%) \\
\hline$R_{11}$ & Fiscal deficit/GDP & 0.188 & 3 \\
$R_{12}$ & Bond issuing volume/fiscal expenditure & 0.128 & 15 \\
$R_{13}$ & Debt service/fiscal income & 0.252 & 8 \\
$R_{14}$ & Bond issuing volume/GDP & 0.114 & 3 \\
$R_{15}$ & Bond issuing volume/deposits outstanding & 0.130 & 4.8 \\
$R_{16}$ & Balance of national debt/GDP & 0.188 & 70 \\
\hline
\end{tabular}

TABle 2: The local government debt risk indicators.

\begin{tabular}{lccc}
\hline Indicators & Definitions & Weights & $\begin{array}{c}\text { Benchmark } \\
(\%)\end{array}$ \\
\hline$R_{21}$ & $\begin{array}{c}\text { Fiscal deficit/GDP } \\
R_{22}\end{array}$ & 0.121 & 3 \\
$R_{23}$ & $\begin{array}{c}\text { Dond issuing volume/fiscal } \\
\text { expenditure }\end{array}$ & 0.290 & 15 \\
$R_{24}$ & $\begin{array}{c}\text { Bond issuing volume/GDP } \\
\text { Balance of local }\end{array}$ & 0.198 & 8 \\
$R_{25}$ & government debt/GDP & 0.257 & 70 \\
\hline
\end{tabular}

The information entropies $C_{j}$ are calculated by the following equation, that $C_{j}=S_{j} \times R_{j}$. And the final weights of indicators are generated by equation (6).

$$
\begin{aligned}
C_{j} & =S_{j} \sum_{i=1}^{p}\left(1-r_{i j}\right), \\
W_{j} & =\frac{C_{j}}{\sum_{j=1}^{p} C_{j}} .
\end{aligned}
$$

Above we briefly summarized how the weights for various indicators, as shown in Tables 1 and 2, are calculated.

2.4. K-Means Clustering Method. Before entering to the discussion of actual results, the analysis method of $K$ means needs to be introduced for risk evaluation in China local governments, to reach a detailed investigation on the risk differences of Chinese provinces. There are two advantages of applying the $K$-means clustering approach. First, it is an efficient clustering algorithm. Secondly, when the clusters are highly dense with nonsignificant differences, $K$-means can produce well clustering results. Below are how clusters are determined by $K$-means method [16].

For a dataset $X=\left\{x_{1}, x_{2}, x_{3}, \ldots, x_{n}\right\}$, there are $n d$-dimensional data point, while $x_{i} \in R_{d}$. The goal is to make the data into $K$ clusters. In the first, the algorithm will divide the dataset into $K$ subsets, $C=\left\{c_{i}, i=1,2, \ldots, K\right\}$. Each subset has a clustering center $u_{i}$. Then, $J\left(c_{k}\right)$ is the sum of the data points distances from the center defined in equation (7), which is calculated by the Euclidean distance.

$$
J\left(c_{k}\right)=\sum_{x \in c_{k}} x_{i}-u_{k}^{2}
$$

The overall goal is to minimize the sum of all $J\left(c_{k}\right)$ in equation (8), which is $J(C)=\sum_{k=1}^{k} c_{k}$.

$$
\begin{aligned}
J(C) & =\sum_{k=1}^{k} c_{k}, \\
& =\sum_{k=1}^{k} c_{k} \sum_{x \in c_{k}} x_{i}-u_{k}^{2} \\
& =\sum_{k=1}^{k} \sum_{i=1}^{n} d_{k i} x_{i}-u_{k}^{2}
\end{aligned}
$$

where $d_{k i}=\left\{\begin{array}{ll}1 & x_{i} \in c_{i} \\ 0 & x_{i} \notin c_{i}\end{array}\right.$ in equation (8) and the mean square error $E$ is used for evaluation in equation (9). In equation (9), $p$ is the data point while $m_{1}$ is the clustering center of the cluster $c_{1}$.

$$
E=\sum_{i=1}^{k} \sum_{p \in c_{1}}\left(\left|p-m_{1}\right|\right)^{2}
$$

The actual $K$-means clustering algorithm starts with a dataset of $n$ points. Then, randomly choose $k$ points for clustering centers $m_{i}(i=1,2,3, \ldots, k)$, following by calculating each point $p$ to its center's distance $d\left(p, m_{i}\right)$, and that is defined in equation (10), where $i=\left\{x_{i 1}, x_{i 2}, \ldots, x_{\text {in }}\right\}$ and $j=\left\{j_{i 1}, j_{i 2}, \ldots, j_{\text {in }}\right\}$ are $n$-dimensional data.

$$
d(i, j)=\sqrt{\left(x_{i 1}-x_{j 1}\right)^{2}+\left(x_{i 2}-x_{j 2}\right)^{2}+\cdots+\left(x_{i n}-x_{j n}\right)^{2}}
$$

For each point $p$, it will go through distance calculations for each cluster, the minimum distance $d\left(p, m_{i}\right)$ will decide which cluster $p$ belongs to. After all points have been evaluated, cluster centers $m_{i}$ will be recalculated by equation (11), where $m_{k}$ is the $K$ th cluster and $N$ is the number of data points in the cluster $K$.

$$
m_{k}=\frac{\left(\sum_{i=1}^{N} x_{i}\right)}{N}
$$

Data points will be assigned to the most similar clusters. The process will iterate until $E$ of equation (9) ceases to decrease, which indicates an optimized clustering has been achieved.

\section{Results and Outcomes}

For the central government's debt risk, the $R_{11}$ to $R_{16}$ indicators are calculated and organized in Table 3 . These outcomes are based on the data from the National Bureau of Statistics and Ministry of Finance, China. The data being 
TABLE 3: The values of the central government debt risk indicators.

\begin{tabular}{lcccccc}
\hline Time & $R_{11}$ & $R_{12}$ & $R_{13}$ & $R_{14}$ & $R_{15}$ & $R_{16}$ \\
\hline 2019 & 1.63 & 2.34 & 0.55 & 1.06 & 0.90 & 0.90 \\
2018 & 1.36 & 2.33 & 0.50 & 1.05 & 1.24 & 0.23 \\
2017 & 1.23 & 2.70 & 0.45 & 1.51 & 0.23 \\
2016 & 1.26 & 3.19 & 0.40 & 1.06 & 0.24 & 0.89 \\
2015 & 1.14 & 2.21 & 0.29 & 0.41 & 0.39 \\
2014 & 0.59 & 0.93 & 0.32 & 0.02 & 0.15 \\
2013 & 0.14 & 0.02 & 0.03 & 0.37 & 0.37 \\
2012 & 0.54 & 0.86 & 0.28 & 0.44 & 0.44 \\
2011 & 0.37 & 1.04 & 0.29 & 0.60 & 0.21 \\
2010 & 0.55 & 1.47 & 0.28 & 0.21 \\
\hline
\end{tabular}

investigated begins from year 2010 to 2019 . The end-date is before the outbreak of the COVID-19 pandemic, which could provide results without the economic impacts of the COVID-19 outbreak both in China and the rest of the world. The impact of COVID-19 will be discussed in Section 4. For risk indicators and their results which are calculated, it is essential that the meaning of these values needs to be elaborated. For $R_{16}$, it is the ratio of balance of national debt to GDP, and the benchmark is $70 \%$. Take the $R_{16}$ of 2019 , for example, its value is 0.17 . Thus, the $R_{16}$ risk is $0.17 / 0.7=0.24$, which is not an abrupt threat while the weighted risk is $0.24 * 0.257=0.109$.

About the risk value of indicators (before weighted), the value of 0.8 to 1 can be interpreted as the risk (represented by the indicator) is now exposed in danger. Moreover, the risk value between 0.5 and 0.8 can be concluded as median threat, meaning that the risk is about to cause problems and need to be handled using careful measures. The value between 0.2 and 0.5 is a minor threat, which requires some sort of intervenes. Moreover, 0 to 0.2 can be considered as risk free, and no immediate actions are required except observation and monitoring. The overall risk of the national government risk is interpreted in the same fashion as the risk indicator above. The values of the national debt's risk indicators are presented in Table 3. The overall national debt (and weighted risk indicators) risk values are organized in Table 4.Source: Data organized from the National Bureau of Statistics of China.

For the local government debt risks, each province's indicators from $R_{21}$ to $R_{25}$ are calculated in the same manner as the nation debt risks analysis. However, the results of every province will be too much to discuss and present here. Therefore, only the overall debt risks (from years 2015 to 2019) of each province are demonstrated in Table 5. According to the risk levels, these provinces are clustered by the $K$-means method (with $K=5$ ) to reach a better understanding of the geographical distribution pattern about the government debt risk. One more thing about the data of local government debts needs to be explained, that the data started from 2015 rather from earlier. It is because that the local government debt was not in the form of local government bonds, which makes it difficult to estimate the overall balance of debt. The data from 2015 onwards would be more precise, because at that time the local governments debts (and previous debts with all kinds of forms) were already reviewed and available in the forms of bonds. The debt risks of the local governments and their clustering, using the $K$-means method, are shown in Table 6.

\section{Discussion}

According to the results, as shown in Table 4, the overall national debt risk has a clear increase in 2015. From 2010 to 2014 , the risk stabilizes in the interval from 0.4 to 0.5 . Within two years, the risks value doubled and reaches 1 , which is exposed to immediate danger. The weighted values of national debt's major indicators are shown in Figure 1. The changes of risk indicators values would reveal the core threats. The major contributor of the national debt risk is $R_{12}$. It rises from 0.1 to 0.3 from 2014 to 2016 , which indicates the government relies on debt much more than the maintained daily functioning. Also, $R_{11}$ shares the same pattern, indicating the fiscal deficit to GDP ratio grows rapidly. However, $R_{16}$ remains at a low and safe level. The balance of debt to GDP keeps around 30\%, providing a certain room for future borrowing. Comparing with major developed countries' $R_{16}$ (more than 100\%), China has a much lower risk which would attract domestic and foreign investors to the Chinese government bonds that may buy more time for China to modify its debt structure.

For the local governments of China, the risk is much more severe. Figure 2 shows the debt risks of all provinces according to the result in Table 5. It can be found out that most local governments are in debt risk danger, in particular, those having the risk value larger than 1 .

The overall local governments' debt risk is the sum of all the provinces' weighted risk values. The weights of provinces are determined by their shares in the national GDP. The local government's overall debt risk starts at 1.3 in 2015; then, in 2016, it grows to a dangerous level of 1.8. Then, it drops down fast in 2017 and has stabilized at 1.5 in recent years. However, the risk shows with a strong upward trend, indicating that the local governments are in trouble of debt, and it is difficult to turn the flow. It may require more investment on infrastructures of poor provinces to stimulate the economy but that means more funding will be needed, especially when most provinces are already in deficit and rely on borrowing.

For provinces of the first cluster in Table 1, their average risk values are around 1, which indicate they are already exposed to danger. For them, further monitoring is required. 
TABLE 4: The overall risk of the central government and weighted risk indicators.

\begin{tabular}{lccccccc}
\hline Time & Overall & $R_{11}$ & $R_{12}$ & $R_{13}$ & $R_{14}$ & $R_{15}$ \\
\hline 2019 & 1.029 & 0.306 & 0.299 & 0.140 & 0.120 & 0.118 \\
2018 & 0.962 & 0.256 & 0.298 & 0.127 & 0.120 & 0.118 \\
2017 & 1.012 & 0.231 & 0.345 & 0.115 & 0.141 & 0.136 \\
2016 & 1.123 & 0.237 & 0.409 & 0.100 & 0.172 & 0.162 \\
2015 & 0.849 & 0.214 & 0.283 & 0.073 & 0.121 & 0.116 \\
2014 & 0.447 & 0.111 & 0.119 & 0.081 & 0.047 & 0.050 \\
2013 & 0.455 & 0.116 & 0.123 & 0.075 & 0.049 & 0.052 \\
2012 & 0.411 & 0.101 & 0.110 & 0.071 & 0.043 & 0.048 \\
2011 & 0.422 & 0.069 & 0.134 & 0.072 & 0.050 & 0.043 \\
2010 & 0.548 & 0.103 & 0.188 & 0.070 & 0.068 & 0.039 \\
\hline
\end{tabular}

TABLE 5: The wages growths of provinces compared to the average.

\begin{tabular}{|c|c|c|c|}
\hline \multicolumn{4}{|c|}{ Wage growth from 2006 to 2019} \\
\hline Zhejiang & -0.71 & Gansu & 0.01 \\
\hline Guangdong & -0.58 & Guangxi & 0.03 \\
\hline Liaoning & -0.56 & Inner Mongolia & 0.06 \\
\hline Shanxi & -0.49 & Hebei & 0.11 \\
\hline Tianjin & -0.42 & Xinjiang & 0.16 \\
\hline Shanghai & -0.35 & Anhui & 0.16 \\
\hline Henan & -0.32 & Jilin & 0.18 \\
\hline Ningxia & -0.31 & Chongqing & 0.19 \\
\hline Tibet & -0.27 & Shaanxi & 0.38 \\
\hline Jiangsu & -0.25 & Sichuan & 0.41 \\
\hline Qinghai & -0.19 & Yunnan & 0.41 \\
\hline Beijing & -0.12 & Jiangxi & 0.47 \\
\hline Fujian & -0.11 & Hubei & 0.70 \\
\hline Shandong & -0.07 & Guizhou & 0.73 \\
\hline Hunan & -0.06 & Hainan & 0.86 \\
\hline Heilongjiang & -0.02 & & \\
\hline
\end{tabular}

Following is the second cluster with average risk value of 1.3. These provinces are in debt trouble and only their strong financial and economical actions could turn the flow. Particularly, for Tianjin, its value jumps up fast from 0.7 to 1.9 in less than five years and the situation could go worse. Then, clusters 3 and 4 have rather high average risk values, which is more than 2 . It can be considered that these local provinces cannot drive them out of the debt mire on their own (neither further borrowing nor economic measures), especially for the Guizhou, Qinghai, and Tibet. However, the situation is not that severe, because these provinces have much lower population as compared to other regions, making the bailout actions from the central government possible and affordable. Meanwhile, Guizhou's debt issue is improving because Guizhou uses its geographical advantages (high attitude with low temperature) well to attract cloud-computing industry to invest. The future finance of Guizhou would perform better with more tax income.

The debt risk of the local governments shows a strong geographical pattern. The provinces with the lowest risk lie in the east coast of China, while provinces in the second cluster (except Tianjin) lie in the middle region. Similarly, the provinces in the third cluster (except Guangxi) are all in the west and north-east regions. The debt risk of the local governments becomes lower from the west to the east of China. The pattern is on account of the provinces on the coast endures a long term of investment due to their conveniency of transportation and supply chain, which booms the economy. Moreover, the study on China population mobility data also records this trend [17]. A better economic efficiency allows government borrowing can turn into highquality future income. This may ease the accumulation of the local government debts. The provinces in the middle and the west have not the same financial boost as the east provinces in the past. This is similar to the conclusion of the research on less developed countries in the EU, which suffer more from the debt problem [18]. Yet, it is not the reason to stop or cut down the relatively poor provinces' borrowing. The structural economic problem needs to be tackled to ensure a balanced development around the country.

One important problem is the divergence of wage around the provinces. Table 5 lists the wage changes compared to the average changes. For instance, Zhejiang's wage growth compared to average change is -0.71 , which indicates the wage in Zhejiang province grows slower than other provinces. Moreover, a slower wage growth provides a comparative advantage in the economic growth, which is reflecting in the potential risks of the local government debts. This means better job opportunities and population inflow in the province. The results of other provinces in the table can also be interpreted in the same manner.Source: Data organized from the National Bureau of Statistics of China. 
TABLE 6: The debt risks of the local governments and their clustering.

\begin{tabular}{|c|c|c|c|c|c|c|c|}
\hline & Average & 2019 & 2018 & 2017 & 2016 & 2015 & Cluster \\
\hline Guangdong & 0.706 & 0.640 & 0.702 & 0.598 & 0.984 & 0.607 & 1 \\
\hline Shanghai & 0.823 & 0.835 & 0.558 & 0.574 & 1.273 & 0.872 & 1 \\
\hline Beijing & 0.887 & 1.002 & 0.649 & 0.832 & 0.944 & 1.008 & 1 \\
\hline Shandong & 1.108 & 1.200 & 1.076 & 0.927 & 1.450 & 0.890 & 1 \\
\hline Jiangsu & 1.121 & 1.097 & 1.014 & 0.964 & 1.432 & 1.099 & 1 \\
\hline Zhejiang & 1.154 & 1.068 & 0.907 & 0.847 & 1.722 & 1.227 & 1 \\
\hline Fujian & 1.181 & 0.936 & 0.884 & 1.279 & 1.567 & 1.238 & 1 \\
\hline Henan & 1.302 & 1.365 & 1.181 & 1.374 & 1.397 & 1.195 & 2 \\
\hline Shanxi & 1.395 & 1.397 & 1.278 & 1.384 & 1.583 & 1.331 & 2 \\
\hline Tianjin & 1.444 & 1.903 & 1.617 & 1.148 & 1.793 & 0.760 & 2 \\
\hline Hubei & 1.446 & 1.648 & 1.203 & 1.158 & 1.887 & 1.336 & 2 \\
\hline Jiangxi & 1.500 & 1.574 & 1.481 & 1.537 & 1.478 & 1.428 & 2 \\
\hline Chongqing & 1.575 & 1.743 & 1.420 & 1.603 & 1.854 & 1.257 & 2 \\
\hline Anhui & 1.617 & 1.519 & 1.827 & 1.519 & 1.703 & 1.515 & 2 \\
\hline Hebei & 1.644 & 1.967 & 1.847 & 1.320 & 1.772 & 1.313 & 2 \\
\hline Sichuan & 1.788 & 1.834 & 1.728 & 1.860 & 2.000 & 1.516 & 3 \\
\hline Liaoning & 1.843 & 1.867 & 1.726 & 1.778 & 2.339 & 1.504 & 3 \\
\hline Shaanxi & 1.844 & 2.015 & 1.737 & 1.612 & 2.257 & 1.600 & 3 \\
\hline Hunan & 1.921 & 2.405 & 1.771 & 1.650 & 2.424 & 1.353 & 3 \\
\hline Jilin & 1.960 & 2.264 & 2.176 & 2.053 & 1.761 & 1.548 & 3 \\
\hline Guangxi & 2.048 & 1.998 & 2.251 & 2.315 & 2.048 & 1.626 & 3 \\
\hline Heilongjiang & 2.191 & 2.519 & 2.785 & 1.949 & 2.039 & 1.661 & 3 \\
\hline Inner Mongolia & 2.245 & 2.275 & 2.158 & 2.146 & 2.759 & 1.889 & 3 \\
\hline Xinjiang & 2.375 & 2.428 & 2.356 & 2.476 & 2.583 & 2.031 & 4 \\
\hline Hainan & 2.525 & 2.542 & 2.651 & 2.708 & 2.895 & 1.829 & 4 \\
\hline Yunnan & 2.604 & 2.341 & 2.420 & 2.758 & 2.961 & 2.541 & 4 \\
\hline Gansu & 2.737 & 3.004 & 2.769 & 2.680 & 2.769 & 2.461 & 4 \\
\hline Ningxia & 2.771 & 3.062 & 3.062 & 2.476 & 2.786 & 2.468 & 4 \\
\hline Guizhou & 3.498 & 2.949 & 3.520 & 3.239 & 3.932 & 3.849 & 4 \\
\hline Qinghai & 4.651 & 5.138 & 4.908 & 4.679 & 4.619 & 3.910 & 4 \\
\hline Tibet & 6.649 & 6.800 & 6.265 & 6.573 & 6.842 & 6.766 & 4 \\
\hline
\end{tabular}

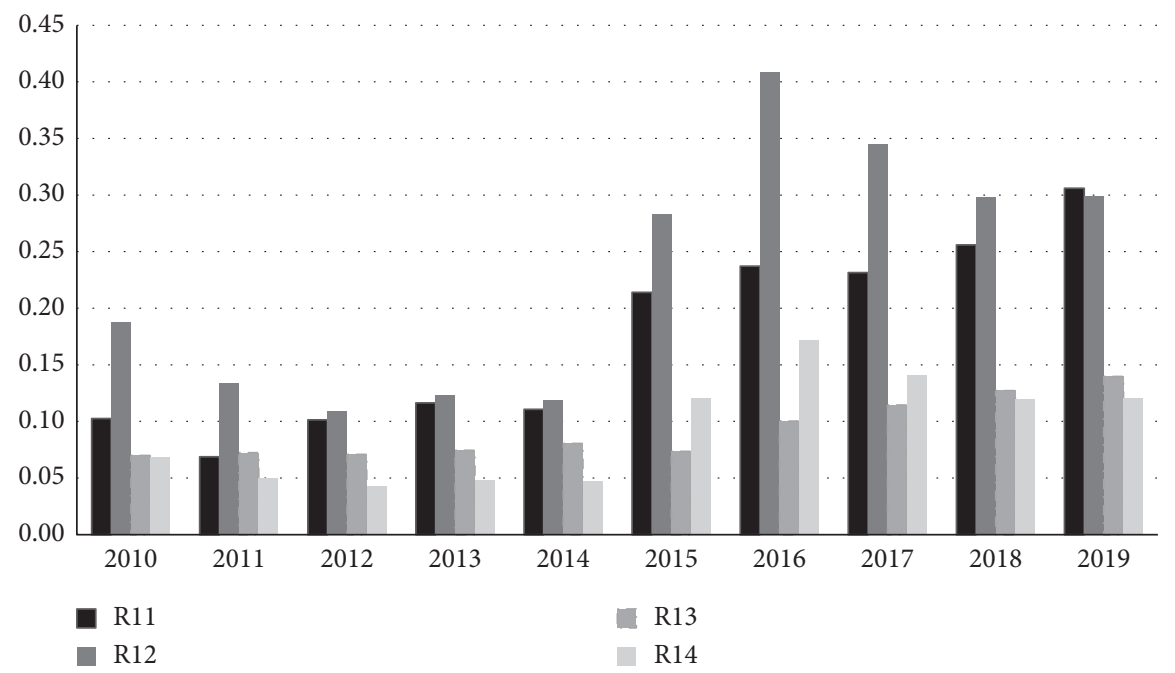

FIGURE 1: The weighted value of national debt's major indicators.

For the provinces having the lowest debt risks (cluster 1), their wage growth is slower with an average of 0.315 , while the figure of provinces in clusters 2 and 3 is around 0.05 which is slightly higher than the average level. The provinces in clusters 4 have a faster wage growth of 0.175 . The wage divergence of provinces correlates with the debt risks. Mobility and relocation of population result in wage divergence, which eventually reshape the economicperformances of different regions. To ensure a balanced development and control the debt risk, the factor of wage and population needs to be investigated further. 




FIgURE 2: The debt risk values of the local governments.

\section{Conclusions and Future Work}

This research investigates the current situation of the debt risk problem, covering both the national government and local governments of China. At this moment, COVID-19 has been spread over the world for two years, strongly disrupting the world economy. The IMF and other institutions concern the potential impacts of sovereign debt crisis and have raised the warning line of debt to GDP ratio as $90 \%$, which we believe may ease or conciliate the market to prevent government bonds' panic selling. Assuming the world's economy will not reach a pleasing level in the short term, sovereign debt risk requires close attention to prevent an upcoming potential debt crisis like Europe in 2018. We evaluated the risk of the central government of China showing that the risk has an increasing trend and reaches the critical level. However, China carried out many direct fiscal expenditures cuts, which is affective to cover the risk. Moreover, the debt to GDP ratio is still on low level as compared to developed countries, which buys more time for China to deal with debt problems. We estimated that the nation debt is not facing immediate threat or risk. According to the general opinion, the debt to GDP ratio does not have to be kept on a low level [19].

For the local governments of China, our evaluations indicated that almost all provinces breached the critical level of debt risk. Few well-developed provinces are free from urgent risk while other rely on borrowing to maintain the debt services. Furthermore, they depend on Beijing funds, making them less willing to improve their fiscal situations $[20,21]$. Due to fiscal transfer payment system, the Beijing fund is considered a rich resource and the local bodies get used to "sleep on," which increases economical welfare [22]. As the risk evaluation indicated, the overall debt will accumulate until the central government can no longer cover. Assuming that the central government is on good position about borrowing, debt risks of local bodies can be handled with right moves. In 2021, the central bank of China tightened the money supply to inefficient industries that is a good start to turn the flow. We observed that the debt risk divergence of the local governments matches the wage divergence-most like the studies on Europe debt crisis. Future research will focus on actual actions for China's balanced development policy. By filling the economic gap of provinces, the population mobility situation and wage divergence would certainly change, which could alter the trend of the local debt risks.

\section{Data Availability}

The data used to support the findings of this study are available from the corresponding author upon request.

\section{Conflicts of Interest}

The authors declare that they have no known competing financial interests or personal relationships that could have appeared to influence the work reported in this study.

\section{Acknowledgments}

This project was sponsored by the National Social Science Fund of China (no. 28BGL118).

\section{References}

[1] J. Beirne and M. Fratzscher, "The pricing of sovereign risk and contagion during the European sovereign debt crisis," Journal of International Money and Finance, vol. 34, no. 1, pp. 60-82, 2013.

[2] K. J. Mitchener and C. Trebesch, "Sovereign debt in the 21st century: looking backward, looking forward," NBER Working Papers, vol. 4, 2021.

[3] C. Reinhart and K. Rogoff, This Time Is Different: Eight Centuries of Financial Folly, Princeton University Press, Priceton, NJ, USA, 2009. 
[4] C. M. Reinhart and K. S. Rogoff, "The forgotten history of domestic debt," The Economic Journal, vol. 121, no. 552, pp. 319-350, 2011.

[5] J. Hilscher and Y. Nosbusch, "Determinants of sovereign risk: macroeconomic fundamentals and the pricing of sovereign debt," Review of Finance, vol. 14, no. 2, pp. 235-262, 2010.

[6] G. Aye, F. Deale, and R. Gupta, "Does debt ceiling and government shutdown help in forecasting the us equity risk premium?" Panoeconomicus, vol. 63, no. 3, pp. 273-291, 2016.

[7] W. Du and J. Schreger, "Local currency sovereign risk," The Journal of Finance, vol. 71, no. 3, pp. 1027-1070, 2016.

[8] S. Ongena and N. V. Horen, "The invisible hand of the government: 《moral suasion》during the European sovereign debt crisis," Cepr Discussion Papers, vol. 2, 2016.

[9] R. Mao, N. N. Liu, and R. Liu, The Expansion of Local Government Debt and the Mechanism of Systemic Financial Risk Triggering, China Industrial Economics, Shunghai, China, 2018.

[10] C. Agiakloglou and E. Deligiannakis, "Sovereign risk evaluation for European Union countries," Journal of International Money and Finance, vol. 103, 2020.

[11] S. Niemann and P. Pichler, "Optimal fiscal policy and sovereign debt crises," Review of Economic Dynamics, vol. 37, 2020.

[12] L. Linnemann, "Default risk premia on government bonds in a quantitative macroeconomic model," Macroeconomic Dynamics, vol. 20, 2016.

[13] N. Croce, T. T. Nguyend, and S. Raymond, "Persistent government debt and aggregate risk distribution," Journal of Financial Economics, vol. 140, 2021.

[14] J. E. Gomez-Gonzalez, O. M. Valencia, and G. A. Sánchez, "How fiscal rules can reduce sovereign debt default risk," Emerging Markets Review, vol. 1, 2021.

[15] M. Zakarya, M. Ali Khattak, I. Ur Rahman, and A. Ali Khan, "Grid high availability and service security issues with solutions," International Journal of Engineering and Technology, vol. 4, no. 6, pp. 723-729, 2012.

[16] T. Ouyang and X. Lu, "Application of two-stage classification method based on $\mathrm{K}$-means function clustering algorithm in financial management," Dynamic Systems and Applications, vol. 29, no. 3, pp. 1014-1026, 2020.

[17] P. Duan, "Influence of China's population mobility on the change of regional disparity since 1978," China Population Resources and Environment, vol. 18, no. 5, pp. 27-33, 2008.

[18] J. Holler, D. Ritzbergergruenwald, and H. Schuberth, "Digging into the composition of government debt in CESEE: a risk evaluation," Focus on European Economic Integration, vol. 6, 2018.

[19] C. M. Reinhart and K. S. Rogoff, "Growth in a time of debt," The American Economic Review, vol. 100, no. 2, pp. 573-578, 2010.

[20] W. R. Lam, A. Schipke, Y. Tan, and Z. Tan, "Resolving China’s zombies: tackling debt and raising productivity," Imf Working Papers, vol. 17, no. 266, p. 1, 2017.

[21] G. Hardin, "The tragedy of the commons," Science, vol. 162, no. 3859 , pp. $1243-1248,1968$.

[22] W. M. Corden and J. P. Neary, "Booming sector and deindustrialisation in a small open economy," The Economic Journal, vol. 36, no. 368, pp. 359-380, 1982. 